\section{Giant Cell Arteritis as a Cause of Acute Myocarditis in the Elderly}

To the Editor

Giant cell arteritis (GCA) is the most common vasculitis in those over age 50 years. The main symptoms are headache, jaw claudication, polymyalgia rheumatica, visual loss, fatigue, and fever. Pericarditis and myocardial infarction due to coronary arteritis have been rarely reported ${ }^{1,2,3}$. Myopericarditis has been described in only 3 patients ${ }^{1,2}$. We describe a new case of acute myopericarditis occurring in a patient with previously undiagnosed GCA.

An 82-year-old woman was admitted to the emergency department for an acute retrosternal chest pain radiating to both arms and lasting for 30 $\mathrm{min}$. She had no cardiovascular risk factors. She had also had 3 months of fatigue, weight loss, polymyalgia, a bitemporal headache, and jaw claudication. Examination revealed tender temporal arteries. There were no symptoms of chronic or acute heart failure. The electrocardiogram (EKG) showed a Q-wave in the anteroseptal leads compatible with myocarditis or myocardial necrosis. C-reactive protein (CRP) was elevated $(59 \mathrm{mg} / \mathrm{l})$ as well as the troponin I level $(1.5 \mathrm{ng} / \mathrm{ml}$ at examination; normal $<0.02$ $\mathrm{ng} / \mathrm{ml}$ ). As there was a high clinical suspicion for GCA associated with myocarditis or coronary vasculitis, intravenous methylprednisolone 1 $\mathrm{mg} / \mathrm{kg}$ was immediately prescribed. She did not receive heparin or antiplatelet aggregation medication. The blood troponin level rose to 18 $\mathrm{ng} / \mathrm{ml} 7 \mathrm{~h}$ later. The pain resolved within $10 \mathrm{~h}$ and the EKG was completely normal within $24 \mathrm{~h}$. Transthoracic echocardiography performed 1 day after admission showed a pericardial effusion and normal left ventricular function and wall motion. Coronary angiography 1 day after admission showed normal coronary arteries. No aortitis was found on the thoracic computed tomography scan. Cardiac magnetic resonance imaging was not performed. There were no anti-DNA or antineutrophil cytoplasmic antibodies and no rheumatoid factors. Blood cultures were sterile and extensive serologic tests (cytomegalovirus, Epstein-Barr virus, parvovirus B-19, $\mathrm{HIV}$, hepatitis $\mathrm{B}$ or $\mathrm{C}$ virus infection, and toxoplasmosis) showed no recent infections. The temporal artery biopsy disclosed a typical mononuclear and GCA infiltrate. Oral prednisone treatment was maintained. The CRP level normalized within a few days. She was discharged with a prescription for prednisone $60 \mathrm{mg}$ once a day and perindopril $4 \mathrm{mg}$ daily. Transthoracic echocardiography 1 year later showed no pericardial effusion and a normal left ventricular ejection fraction. Prednisone was withdrawn 2 years after diagnosis. No relapse occurred during prednisone tapering.

This patient had typical but undiagnosed GCA before hospital admission. We think that she also suffered from myopericarditis rather than acute coronary syndrome (ACS), as coronarography and echography results were normal and the Q-wave fully resolved. However, we cannot exclude ACS, which would have resolved rapidly after the introduction of corticosteroids (CS), because the efficacy of CS is very impressive in cases of GCA. A thrombus resolving spontaneously may also have occurred, but this hypothesis seems unlikely. Acute infectious myocarditis seems unlikely because the patient had prompt resolution of all symptoms and biological abnormalities after the introduction of CS, and that disease preferentially affects young people.

Acute myopericarditis is exceedingly rare in GCA: only 3 cases have been reported. The clinical presentation can be severe: Teixeira, et $a l^{1}$ described 2 patients with myopericarditis and global heart failure before
GCA was diagnosed. No coronarography was performed in these patients ${ }^{1}$. GCA myopericarditis had a favorable outcome with high-dose CS therapy in all published reports. The pathophysiology of GCA myocarditis is unknown; diffuse vasculitis of small myocardial vessels has been suspected ${ }^{4}$.

Our observations further demonstrate that GCA should be considered as a cause of heart pain, due to either acute myopericarditis or acute coronary syndrome, in patients over 50 years of age. Questioning aged patients with myopericarditis for extracardiac symptoms is essential, as GCA is very sensitive to CS, and CS are usually not prescribed for myopericarditis or coronary diseases. The diagnosis can be confirmed by temporal artery biopsy. We advise that investigation for GCA by temporal artery biopsy should be performed in patients over age 50 years with myopericarditis in a context of biological inflammation, even in the absence of suggestive clinical signs ${ }^{1}$. GCA should be recognized early in patients with myopericarditis/coronary vasculitis because the clinical course can be severe if CS therapy is delayed.

GRÉGORY PUGNET, MD, Service de Médecine Interne, Centre Hospitalier Universitaire (CHU) de Toulouse, Université de Toulouse, Toulouse, Service de Pharmacologie Clinique, Centre Midi-Pyrénées de Pharmacovigilance, de Pharmacoépidémiologie et d'Informations sur le Médicament, Unité de Pharmacoépidémiologie INSERM U1027, CHU de Toulouse, Université de Toulouse, Faculté de Médecine; ATUL PATHAK, MD, PhD, Service de Pharmacologie Clinique, Centre Midi-Pyrénées de Pharmacovigilance, de Pharmacoépidémiologie et d'Informations sur le Médicament, Unité de Pharmacoépidémiologie INSERM U1027, CHU de Toulouse, Université de Toulouse, Faculté de Médecine, Service de Cardiologie, CHU de Toulouse, Université de Toulouse; NICOLAS DUMONTEIL, MD, Service de Cardiologie, CHU de Toulouse, Université de Toulouse; LAURENT SAILLER, MD, PhD, Service de Médecine Interne, CHU de Toulouse, Université de Toulouse, Service de Pharmacologie Clinique, Centre Midi-Pyrénées de Pharmacovigilance, de Pharmacoépidémiologie et d'Informations sur le Médicament, Unité de Pharmacoépidémiologie INSERM U1027, CHU de Toulouse, Université de Toulouse, Faculté de Médecine, Toulouse, France.

Address correspondence to Dr. G. Pugnet, Service de Médecine Interne, CHU Toulouse-Purpan, Place du Docteur Baylac, TSA 40031, 31059

Toulouse cedex, France. E-mail: gpugnet@cict.fr

\section{REFERENCES}

1. Teixeira A, Capitaine E, Congy F, Herson S, Cherin P. [Myopericarditis during Horton disease]. Rev Med Interne 2003;24:189-94.

2. Guindon A, Rossi P, Bagneres D, Aissi K, Demoux A, Bonin-Guillaume $\mathrm{S}$, et al. [Pericarditis: a giant cell arteritis manifestation]. Rev Med Interne 2007;28:326-31.

3. Lie JT. Coronary vasculitis. A review in the current scheme of classification of vasculitis. Arch Pathol Lab Med 1987;111:224-33.

4. Kodama M, Matsumoto Y, Fujiwara M, Zhang SS, Hanawa H, Itoh $\mathrm{E}$, et al. Characteristics of giant cells and factors related to the formation of giant cells in myocarditis. Circ Res 1991;69:1042-50.

J Rheumatol 2011;38:11; doi:10.3899/jrheum.110609

Personal non-commercial use only. The Journal of Rheumatology Copyright @ 2011 . All rights reserved. 